\title{
Toxoplasmosis cerebral: paresia del miembro superior única, una manifestación poco usual
}

\section{Cerebral toxoplasmosis: paresis of the single upper limb, an unusual manifestation}

\author{
Juan Ramón y Cajal Calvo, ${ }^{*}$ Agustín Sancho Saldaña, ${ }^{\ddagger}$ María José Gimeno Peribáñez* \\ Citar como: Ramón y Cajal CJ, Sancho SA, Gimeno PMJ. Toxoplasmosis cerebral: paresia del miembro superior única, \\ una manifestación poco usual. Acta Med GA. 2022; 20 (1): 79-82. https://dx.doi.org/10.35366/103562
}

\section{Resumen}

Introducción: La toxoplasmosis cerebral es una de las infecciones oportunistas más comunes en los pacientes con virus de inmunodeficiencia humana $(\mathrm{VIH})$, siendo la principal causa de lesiones cerebrales en esta población originando secuelas neurológicas importantes y alcanzando una elevada mortalidad en este grupo de pacientes. Caso clínico: Paciente femenino que acude al servicio de urgencias con fiebre, cefalea, náusea y paresia del miembro superior izquierdo sin antecedentes médicos relevantes conocidos. Los estudios analíticos revelan unos niveles disminuidos de CD4+ y serologías positivas para $\mathrm{VIH}$. Se estudió con el uso de métodos complementarios. La tomografía computarizada (TC) y la resonancia magnética (RM) mostraron imágenes compatibles con infección del tipo de la toxoplasmosis. Se realizó serología para el parásito que resultó positiva, dando el diagnóstico definitivo. Se trató con pirimetamina-sulfadiazina durante seis semanas. Conclusión: La toxoplasmosis cerebral es frecuente en pacientes con VIH, por lo que un diagnóstico temprano tanto del VIH como de la toxoplasmosis es indispensable para un tratamiento adecuado y evitar futuras comorbilidades.

Palabras clave: VIH, inmunosupresión, toxoplasmosis, cerebral, paresia.

\section{INTRODUCCIÓN}

La toxoplasmosis es una infección causada por Toxoplasma gondii, un protozoario intracelular obligado. La infección en pacientes inmunocompetentes puede pasar inadverti-

\section{Abstract}

Introduction: Cerebral toxoplasmosis is one of the most common opportunistic infections in HIV patients, being the main cause of brain lesions in this population, causing important neurological sequelae and reaching a high mortality rate in this group of patients. Clinical case: A female patient came to the emergency department with fever, headache, nausea, and left upper limb paresis with no known relevant medical history. Laboratory studies reveal decreased CD4+ levels and positive serologies for HIV. It was studied with the use of complementary methods. CT and MRI showed images compatible with infection for toxoplasmosis. Serology was performed for the parasite that was positive, giving the definitive diagnosis. He was treated with pyrimethamine-sulfadiazine for a six-weeks. Conclusion: Cerebral toxoplasmosis is frequent in patients with HIV, so an early diagnosis of both HIV and toxoplasmosis is essential for adequate treatment, avoiding future comorbidities.

Keywords: HIV, immunosuppression, toxoplasmosis, cerebral, paresis. da; sin embargo, en los pacientes inmunocomprometidos, en especial en aquéllos con infección por el virus de la inmunodeficiencia humana $(\mathrm{VIH})$, la forma más común de presentación es la encefalitis, es la principal causa de lesiones cerebrales en esta población.

\footnotetext{
* Servicio de Radiodiagnóstico del Hospital Clínico Universitario "Lozano Blesa". España.

₹ Servicio de Neurología del Hospital Universitario Arnau de Vilanova. Lérida, España.
}

Correspondencia:

Juan Ramón y Cajal Calvo

Correo electrónico: jramonycajalc@gmail.com

Aceptado: 18-02-2021.

www.medigraphic.com/actamedica 


\section{CASO CLÍNICO}

Mujer de 31 años, natural de Nigeria, residente en España desde hace 12 años, derivada al Servicio de Urgencias por un cuadro de cefalea frontal, náusea y vómito de cinco días de evolución, acompañándose en las últimas 24 horas de fiebre y pérdida de fuerza en la extremidad superior izquierda. No refería alergias y un episodio de apendicitis aguda era su único antecedente conocido.

A su llegada, la paciente se encontraba somnolienta y con bradipsiquia. En la exploración neurológica destacó déficit motor 3-4/5 en extremidad superior izquierda sin otro dato de focalización. Los reflejos osteotendinosos resultaron normales. En la exploración física, se observaron lesiones micóticas orales y se encontró una hepatomegalia dolorosa con el peristaltismo conservado, sin otros hallazgos de interés.

En los análisis iniciales destacaron los siguientes parámetros: hemoglobina $10.5 \mathrm{~g} / \mathrm{dL}(12-16)$, hematocrito $30.8 \%$ (36-48\%), 3,200 leucocitos $/ \mathrm{mm}^{3}$ (4-11), lactato deshidrogenasa (LDH) $631 \mathrm{U} / \mathrm{L}(135-225)$. El resto de los parámetros fueron normales. El hemocultivo y urocultivo resultaron negativos. El estudio de inmunidad reveló unos parámetros alterados con CD4 de 450 (valores normales 500-1,600 células $\times \mathrm{mm}^{3}$ ), CD8 de 328.5 (valores normales 375-1,100 células $\times \mathrm{mm}^{3}$ ), VIH positivo con carga viral de 4,59.10 . El estudio serológico fue negativo para hepatitis B y C, virus de Epstein-Barr y citomegalovirus (CMV). Por último, se llevó a cabo un frotis bucal por la presencia de las lesiones micóticas que resultó positivo para Candida albicans.

Se realizó una tomografía axial computarizada (TAC) cerebral en la que se observaron numerosas áreas hipodensas frontoparietales derechas, temporoparietales izquierdas y cerebelosas bilaterales que no realzaron tras la administración de contraste y eran compatibles con regiones de encefalitis (Figura 1).

Durante el ingreso, el paciente no mejoró neurológicamente, por lo que se realizó una RM (resonancia magnética) cerebral, que mostró múltiples lesiones anulares que afectaban a ambos hemisferios cerebelosos, mesencéfalo, tálamo y ganglios basales. Estas lesiones presentaron un predominio central hipointenso en secuencias ponderadas en T1 e hiperintensidad en T2 y FLAIR (Figura 2).

Estos hallazgos fueron altamente sugestivos de toxoplasmosis cerebral con afectación supra e infratentorial a nivel talámico y protuberancial. Tras la sospecha diagnóstica, se determinaron IgG específicas para Toxoplasma spp. que fueron positivas con un título de $420.7 \mathrm{U} / \mathrm{mL}$.

Se interpretó el cuadro clínico como una toxoplasmosis cerebral en el contexto de una infección por VIH-SIDA (C3) no conocida. Se inició tratamiento con sulfadiazina y pirimetamina intravenosa junto con tratamiento rehabilitador, mejorando la clínica neurológica a lo largo del ingreso. A la semana, presentó dolor en el territorio esofágico, realizándose una fibrogastroscopia donde se vio una esofagitis, que anatomopatológicamente pareció asociada con micosis (se descartó por serología infección por Aspergillus). Además, presentó lesiones candidiásicas orales que fueron tratadas con fluconazol y después con caspofungina, con resolución de las mismas.

La paciente fue dada de alta con tratamiento antirretroviral, con una cifra de CD4 al alta de 56 por $\mathrm{mm}^{3}$ y una carga viral de 214 partículas de RNA viral.

\section{DISCUSIÓN}

Toxoplasma gondii es un parásito protozoario intracelular ubicuo, que afecta aproximadamente a una tercera parte de la población, ${ }^{1}$ causando infecciones subclínicas en la mayoría de los individuos inmunocompetentes, pero con consecuencias devastadoras en los inmunocomprometidos. ${ }^{2}$ En estos últimos, la toxoplasmosis cerebral se produce por la reactivación de quistes cerebrales latentes, ${ }^{3}$ siendo la causa más común de lesiones ocupantes de espacio en individuos con $\mathrm{VIH}{ }^{2}$

En pacientes que cursan con $\mathrm{VIH}$, la toxoplasmosis cerebral es común con un recuento de CD4 $+<200$ células/

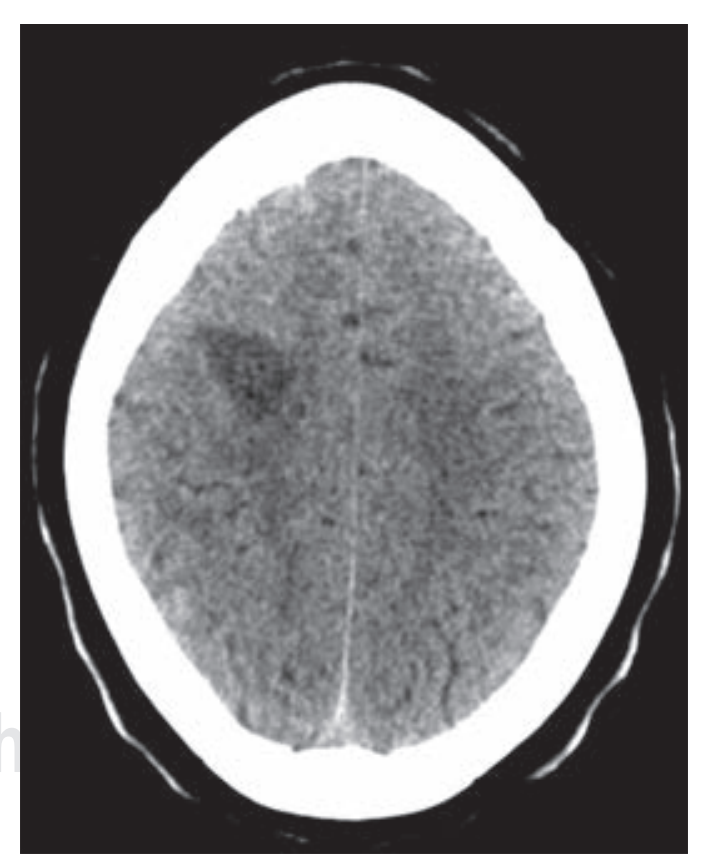

Figura 1: Tomografía axial computarizada cerebral sin contraste, corte axial. Se visualiza una lesión hipodensa frontoparietal derecha con participación córtico-subcortical que ejerce un discreto efecto de masa correspondiente con foco de encefalitis. 

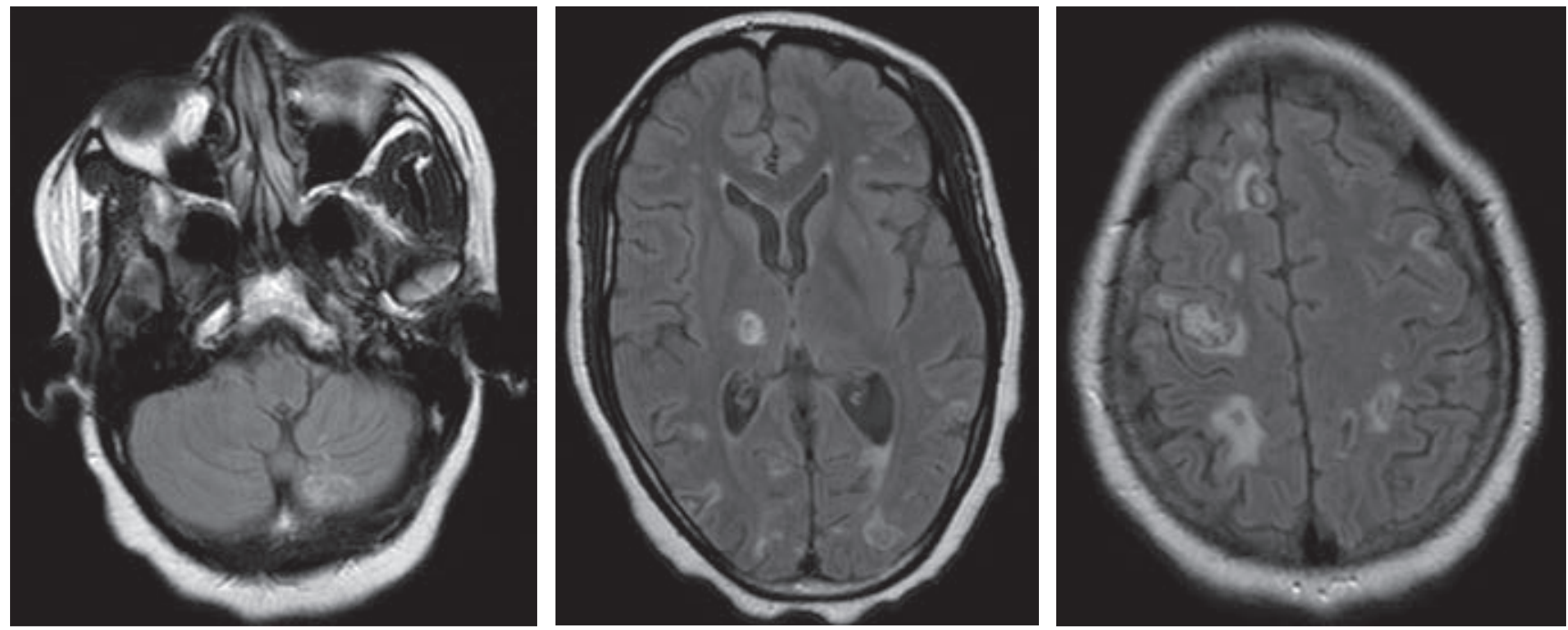

Figura 2: Resonancia magnética cerebral, cortes axiales, secuencias ponderadas en T2 y FLAIR. Se visualizan múltiples áreas hiperintensas con morfología en diana de localización córtico-subcortical supra e infratentorial correspondientes con áreas de encefalitis.

mm, ${ }^{4}$ manifestándose clínicamente como un deterioro neurológico subagudo, variando en función del número y la topografía de las lesiones.

La cefalea, los déficits focales, fiebre, bradipsiquia y las crisis epilépticas son las manifestaciones más frecuentes. ${ }^{5}$ Entre otras manifestaciones clínicas también se han descrito náusea, vómito, fiebre, alteraciones de la conciencia, disfonía y alteraciones visuales. ${ }^{6}$ Sin tratamiento, la evolución es hacia el estupor, coma y el fallecimiento. ${ }^{2}$

El diagnóstico se confirma con un resultado positivo de T. gondii en líquido cefalorraquídeo (LCR) mediante PCR o con biopsia cerebral, pero esto no siempre es posible. Los datos clínicos y de neuroimagen compatibles, sumados a una IgG positiva para $T$. gondii en suero tiene una sensibilidad combinada de $90 \%$ para establecer el diagnóstico.`

La biopsia se considera el estándar de oro para realizar el diagnóstico definitivo, pero debido a que las lesiones se encuentran en la mayoría de las ocasiones en localizaciones profundas y de difícil acceso, se opta por utilizar técnicas de neuroimagen (TAC o RM) y comenzar tratamiento empírico previo a la confirmación microbiológica. En la TAC se visualizan lesiones únicas o múltiples de aspecto hipodenso, habitualmente con edema perilesional de gran cuantía que pueden condicionar un efecto masa y con captación de contraste muestran un patrón de anillo con edema perilesional en ganglios basales (48\%), lóbulo frontal $(37 \%)$ y parietal $(37 \%){ }^{8}$

Sin embargo, no hay datos patognomónicos de la neuroinfección por Toxoplasma gondii, ya que entre los diagnósticos diferenciales que muestran el patrón de anillo por el contraste encontramos los linfomas primarios del sistema nervioso central (SNC), el glioblastoma multiforme, las metástasis cerebrales, abscesos cerebrales e infartos cerebrales.

En los últimos años, se ha utilizado la resonancia magnética nuclear (RMN) con espectroscopia donde se describe un patrón inflamatorio, con un aplanamiento en el nivel de captación de $\mathrm{N}$-acetil aspartato (NAA), un pequeño aumento de colina (Ch) y un pico de lípidos y lactato.

El tratamiento de elección es con pirimetamina-sulfadiazina durante al menos seis semanas. ${ }^{1}$ Se debe extender el tiempo del tratamiento en caso de que exista una respuesta incompleta durante las primeras semanas o en caso de enfermedad con componentes clínicos o radiológicos extensos. En caso de alergia o contraindicación para el uso de la sulfadiazina, el tratamiento habitual alternativo es con pirimetamina-clindamicina. ${ }^{6}$

\section{CONCLUSIÓN}

La toxoplasmosis cerebral es una de las infecciones oportunistas más comunes en los pacientes con VIH, y se menciona que hasta la mitad de estos casos presentan serología positiva para toxoplasmosis, pudiendo desarrollar cuadros de encefalitis que, a su vez, pueden producir secuelas neurológicas importantes, alcanzando una elevada mortalidad, por lo que tener un índice de sospecha alto e iniciar tratamiento precoz es esencial para evitar futuras complicaciones en este grupo de pacientes. 


\section{REFERENCIAS}

1. Dunay IR, Gajurel K, Dhakal R, Liesenfeld O, Montoya JG. Treatment of toxoplasmosis: historical perspective, animal models, and current clinical practice. Clin Microbiol Rev. 2018; 31 (4): e00057-17. doi: 10.1128/CMR.00057-17.

2. Vidal JE. HIV-related cerebral toxoplasmosis revisited: current concepts and controversies of an old disease. J Int Assoc Provid AIDS Care. 2019; 18: 2325958219867315 . doi: 10.1177/2325958219867315.

3. Lyons RE, McLeod R, Roberts CW. Toxoplasma gondii tachyzoitebradyzoite interconversion. Trends Parasitol. 2002; 18 (5): 198-201. doi: 10.1016/S1471-4922(02)02248-1.

4. Parlog A, Schluter D, Dunay IR. Toxoplasma gondii-induced neuronal alterations. Parasite Immunol. 2015; 37 (3): 159-170.
5. Mamidi A, DeSimone JA, Pomerantz RJ. Central nervous system infections in individuals with HIV-1 infection. J Neurovirol. 2002; 8 (3): 158-167. doi: 10.1080/13550280290049723.

6. Hernandez AV, Thota P, Pellegrino D, Pasupuleti V, Benites-Zapata VA, Deshpande A et al. A systematic review and meta-analysis of the relative efficacy and safety of treatment regimens for HIV-associated cerebral toxoplasmosis: is trimethoprim-sulfamethoxazole a real option? HIV Med. 2017; 18 (2): 115-124.

7. Selby JV, Friedman GD, Quesenberry CP Jr, Weiss NS. A case-control study of screening sigmoidoscopy and mortality from colorectal cancer. N Engl J Med. 1992; 326 (10): 653-657.

8. Greenway MRF, Sacco KA, Burton MC. In deep: cerebral toxoplasmosis. Am J Med. 2017; 130 (7): 802-804. 